\title{
Comparison of Retention Rates of Fissure Sealants Using Two Flowable Restorative Materials and a Conventional Resin Sealant: Two-Year Follow-Up
}

\author{
Aylin Akbay Oba ${ }^{a}$ Işıl Şaroğlu Sönmez ${ }^{a} \quad$ Ertuğrul Ercan $^{b} \quad$ Türksel Dülgergil ${ }^{b}$ \\ Departments of a Pediatric Dentistry and ${ }^{b}$ Operative Dentistry, School of Dentistry, University of Kırıkkale, \\ Kırıkkale, Turkey
}

\section{Key Words}

Flowable composite $\cdot$ Retention · Fissure sealant

\begin{abstract}
Objective: The purpose of this clinical study was to compare the retention rates of two flowable restorative systems (Admira Flow and Grandio Flow) with that of a conventional resin-based sealant (Fissurit F). Materials and Methods: The study was planned as a clinical trial with a split-mouth design. A total of 122 sealants (38 Admira Flow, 41 Grandio Flow, 43 Fissurit F) were randomly applied to completely erupted permanent molars in 35 patients aged 9-20 years and followed up for 24 months. Data were analyzed using Pearson's $\chi^{2}$ and multiple comparison tests. Results: At the end of the followup period, Fissurit $\mathrm{F}$ had higher retention rates $(81.0 \%)$ than both Admira Flow (60.5\%) and Grandio Flow (57.1\%), with $\mathrm{p}<$ 0.05 . However, there was no significant difference in caries development among groups ( $p>0.05)$. Conclusion: The two flowable composite resin materials used as fissure sealant were less retentive than the conventional resin sealant.
\end{abstract}

Copyright $\odot 2011$ S. Karger AG, Basel

\section{Introduction}

Recent studies have shown a decrease in the incidence of smooth-surface and approximal caries partly as a result of improved oral hygiene and the use of fluoride agents. However, these measures have been less effective in reducing caries on occlusal surfaces, whose complex fissure morphology allows for plaque accumulation and makes mechanical cleaning difficult [1-3]. For these reasons, fissure sealants have been recommended and are frequently used in many countries for the prevention of fissure caries $[4,5]$.

Over the past 30 years, various materials and techniques have been developed to improve pit-and-fissure sealant quality and longevity. Bisphenol A glycidylmethacrylate, which has formed the basis of composite material, is generally used in sealants as well; thus, in line with developments that have taken place in composite materials, the composition of sealants has also changed [6]. Filled sealants have been shown to exhibit greater microhardness and less wear than unfilled sealants [7] because it is assumed that filled flowable restorative material might provide better retention rates than a conventional sealant because the filled material possesses higher viscosity, undergoes less polymerization shrinkage, has greater microhardness and shows better abrasion resistance than the unfilled material; However, the author [7] reported slightly lower retention rates for teeth sealed with flowable material compared to traditional composite. There are several studies recommending the use of flowable resin composites as fissure sealants $[8,9]$. However, Kwon and Park [10] found the higher viscosity of flowable composites to result in voids, whereas no voids were detected with conventional sealants. Duangthip and Lussi [11] also reported

\section{KARGER \\ Fax +4161306 1234 \\ E-Mail karger@karger.ch}

www.karger.com (c) 2011 S. Karger AG, Basel

1011-7571/12/0213-0234\$38.00/0

Accessible online at:

www.karger.com/mpp
Iș1 Saroğlu Sönmez

Kırıkkale Üniversitesi, Diș Hekimliği Fakültesi

Pedodonti ABD

Kirıkkale (Turkey)

Tel. +90 318224 3618, E-Mail isilsaroglu@yahoo.com 
classical sealants such as Fissurit $\mathrm{F}$ to exhibit significantly less microleakage than flowable composites.

Corona et al. [12] suggested that while flowable restorative materials might be used as sealants, the variation in viscosity, composition and physical properties of the various flowable materials available required clinical testing before any general recommendation regarding their use as fissure sealants could be made.

To date, however, few studies have evaluated the retention rates of different flowable resin composites used as fissure sealant $[7,11,12]$, and none of these studies include reviews of the silorane-based flowable composite Admira Flow (Voco, Cuxhaven, Germany) or the nanoresin material Grandio Flow (Voco). Therefore, the aim of this clinical study was to evaluate the retention rates of the flowable restorative systems Admira Flow and Grandio Flow and compare them with a conventional resin-based sealant (Fissurit F, Voco) over a 2-year period.

\section{Materials and Methods}

The study was conducted among 35 patients aged 9-20 years who attended the School of Dentistry, Kirikkale University, for routine dental care. Only patients who presented with caries-free, completely erupted first/second permanent molars with deep and retentive pits and fissures were included in the study. Detailed clinical and radiographic examinations were conducted by two examiners, and teeth that did not meet these criteria were excluded from the study.

The study protocol was approved by the National Educational Management of Kirikkale County, Kirikkale, Turkey. Parents of participating children were fully informed of the nature of the study and signed a detailed consent form.

The study was conducted using one silorane-based flowable composite (Admira Flow), one nanoresin flowable composite (Grandio Flow) and one conventional resin sealant (Fissurit F). Detailed information on material composition is given in table 1. Sealants were applied to a total of 122 maxillary and mandibular left and right permanent molars. Materials were randomly placed, with each material used on at least 1 tooth in each subject. Prior to sealing, teeth were cleaned with a prophylaxis brush using nonfluoridated pumice, isolated with cotton rolls and a saliva ejector, etched with $37 \%$ phosphoric acid (Super etch, SDI) for 20 s, rinsed for $15 \mathrm{~s}$ and dried for $5 \mathrm{~s}$ until the tooth surface was chalky white. Materials were applied and cured (Chromalux-E plus, Germany) according to the manufacturer's instructions.

Teeth were examined by an experienced dentist using a mirror and explorer at 12 and 24 months and scored for retention as follows [10]: total retention (TR), i.e. total retention of sealant on the occlusal surface $=1$; partial loss (PL), i.e. fracture and/or loss of material $=2$; total loss (TL), i.e. absence of sealant on the occlusal surface $=3$. Teeth were also evaluated for caries as follows: present $($ cavitated lesion $)=1$; absent $($ no cavitated lesion $)=2$.

Retention of Two Flowable Composites as Fissure Sealant
Table 1. Compositions, specifications and manufacturers of the materials used

\begin{tabular}{ll}
\hline Material & Contents \\
\hline $\begin{array}{l}\text { Admira Flow } \\
\text { (Voco, Cuxhaven, } \\
\text { Germany) }\end{array}$ & $\begin{array}{l}\text { flowable, light-curing filling material based } \\
\text { on Ormocer dimethacrylates, Ormocer ini- } \\
\text { tiators, inorganic microparticles, silicate fill- } \\
\text { ers, fumed silica and different additives }\end{array}$ \\
\hline $\begin{array}{l}\text { Grandio Flow } \\
\text { (Voco, Cuxhaven, } \\
\text { Germany) }\end{array}$ & $\begin{array}{l}\text { flowable, light-curing nanohybrid compos- } \\
\text { bilizers, pigments and additives }\end{array}$ \\
$\begin{array}{l}\text { Fissurit F } \\
\text { (Voco, Cuxhaven, } \\
\text { Germany) }\end{array}$ & $\begin{array}{l}\text { resin-based pit and fissure sealant, } \\
\text { silicon dioxide }\end{array}$ \\
\hline
\end{tabular}

Table 2. The distribution of evaluated teeth by material type after 12 and 24 months

\begin{tabular}{lcc}
\hline Material type & 12 months & 24 months \\
\hline Admira Flow & 36 & 38 \\
Grandio Flow & 32 & 35 \\
Fissurit F & 35 & 37 \\
\hline Total & 103 & 110 \\
\hline
\end{tabular}

Data were analyzed using Pearson's $\chi^{2}$ and multiple comparison tests, with the significance level set at $\mathrm{p} \leq 0.05$. Of the 122 teeth sealed, 103 were available for evaluation at 12 months and 110 for evaluation at 24 months.

\section{Results}

The distribution of evaluated teeth by material type is shown in table 2 while the distribution of material retention rates at 12 and 24 months by material type is given in table 3. At the 12-month follow-up examination, the TR rates were $85.7 \%$ for Fissurit F, $69.4 \%$ for Admira Flow and $59.3 \%$ for Grandio Flow. The PL rates were $14.3 \%$ for Fissurit F, 16.6\% for Admira Flow and 15.6\% for Grandio Flow, and the TL rates were $0 \%$ for Fissurit F, $14 \%$ for Admira Flow and 25.1\% for Grandio Flow.

The differences in TR, PL and TL rates were statistically significant within each group ( $p>0.05)$. At 24 months of follow-up, TR rates were $81 \%$ for Fissurit F, 60.5\% for Admira Flow and 57.1\% for Grandio Flow; PL 
Table 3. Distribution of various retention criteria (TR, PL and TL) of three materials after 12 and 24 months

\begin{tabular}{|c|c|c|c|c|c|c|c|c|}
\hline & \multicolumn{2}{|c|}{ Admira Flow } & \multicolumn{2}{|c|}{ Grandio Flow } & \multicolumn{2}{|l|}{ Fissurite F } & \multicolumn{2}{|l|}{ Total } \\
\hline & 12 months & 24 months & 12 months & 24 months & 12 months & 24 months & 12 months & 24 months \\
\hline PL & $6(16.6)$ & $9(23.6)$ & $5(15.6)$ & $5(14.2)$ & $5(14.3)$ & $6(16.2)$ & $16(15.5)$ & $20(18.1)$ \\
\hline TL & $5(14)$ & $6(15.9)$ & $8(25.1)$ & $10(28.7)$ & $0(0)$ & $1(2.8)$ & $13(12.7)$ & $17(15.6)$ \\
\hline
\end{tabular}

Groups identified by different superscript letters were significantly different at the $\mathrm{p}<0.05$ level. Figures in parentheses are percentages.

rates were 16.2\% for Fissurit F, 23.6\% for Admira Flow and $14.2 \%$ for Grandio Flow, and TL rates were $2.8 \%$ for Fissurit F, 14.2\% for Admira Flow and 28.7\% for Grandio Flow (table 3).

Regarding the corresponding rates at 24 months, Fissurit $\mathrm{F}$ had $2.8 \%$, Admira Flow $7.9 \%$ and Grandio Flow $2.9 \%$. The observed differences were not statistically significant ( $\mathrm{p}>0.05)$.

At 24 months TR rates for first and second molars were $89.6 \%$ and $76.8 \%$, respectively, and this difference was not statistically significant $(\mathrm{p}>0.05)$.

\section{Discussion}

The findings of this clinical study suggest that flowable composite material used as a fissure sealant was less retentive than conventional sealant material. At 12 months, the retention rate of the Fissurit F group (85.7\%) was statistically greater than that of the Admira Flow group (69.4\%), which is comparable to those of Dukić et al. [13], who reported 12-month retention rates of $83.3 \%$ for Tetric Flow, 81.5\% for Admira Seal, 81.5\% for Fissurit FX, 75.9\% for Helioseal Clear Chroma and 74.6\% for Admira Flow.

Our findings regarding sealant ability differ from those of other studies by Dukić and Glavina [14, 15], who reported that the performance of flowable composites used as fissure sealants was comparable to that of classic sealing material. The difference in findings among studies may be related to differences in rheological properties inherent in the specific materials tested [16].

In the present study, despite the lower retention rates of the flowable composite resins Admira Flow and Grandio Flow in comparison to the traditional sealant Fissurit $\mathrm{F}$ at 24 months, the differences in caries formation between the flowable composites and the traditional sealant were not statistically significant. As observed in routine clinical practice, even after the loss of a sealant, its effect in terms of caries prevention can continue for a significant amount of time. Partially sealed teeth have been reported to be considerably less susceptible to decay than unsealed teeth [17], possibly due to the presence of sealant remnants at the bottom of the fissure [18].

A number of factors are known to influence sealant retention, including sealant type, tooth type, operator skill and patient age. Similar to previous studies $[19,20]$, the present study found sealant retention was better on first molar teeth than on second molar teeth. This finding may be due to the difficulties in isolating second molars in comparison to first molars.

The results of this clinical study suggest that flowable composite materials, i.e. Admira Flow and Grandio Flow, are not as retentive as the conventional sealant material Fissurit $\mathrm{F}$ as a fissure sealant. It is possible that, in comparison to flowable composites, conventional sealants have greater fluidity, which allows them to penetrate into the deeper regions of fissures, thus making them more retentive than flowable composites. They were even more resistant against masticatory forces. Moreover, although sealants with small amounts of inorganic filler might be expected to perform better than resin sealants without fillers in terms of polymerization shrinkage and thus sealing capacity, the minimal amount of material used in sealing makes the amount of polymerization shrinkage negligible in actual clinical practice.

\section{Conclusions}

At the 24-month evaluation, the flowable composite materials used as sealants in this study had significantly lower retention rates than that of a conventional resinbased sealant. 


\section{References}

$>1$ Ripa LW, Leske GS, Sposato A, Rebich T: Supervised weekly rinsing with a $0.2 \%$ neutral $\mathrm{NaF}$ solution: final results of a demonstration program after six school years. J Public Health Dent 1983;43:53-62.

-2 Selwitz RH, Nowack-Raymer R, Driscoll WS, Li SH: Evaluation after 4 years of the combined use of fluoride and dental sealants. Community Dent Oral Epidemiol 1995; 23:30-35.

$>3$ Sterritt GB, Frew RA, Rozier RG, Brunelle JA: Evaluation of a school based fluoride mouthrinsing and clinic based sealant program on a non-fluoridated island. Community Dent Oral Epidemiol 1990;18:288-293.

4 Ripa LW: The current status of pit and fissure sealants: a review. J Can Dent Assoc 1985;51: 367-368.

$>5$ Güngör HC, Altay N, Alpar R: Clinical evaluation of a polyacid-modified resin composite-based fissure sealant: two-year results. Oper Dent 2004;29:254-260.

6 Turgut MD, Güngör HC, Ölmez S: Clinical evaluation of a flowable polyacid-modified resin composite used as fissure sealant in primary teeth: 1-year results. Hacettepe Diş Hek Fak Derg 2005;29:2-7.
7 Autio-Gold JT: Clinical evaluation of a medium filled flowable restorative material as a pit and fissure sealant. Oper Dent 2002;27: 325-329.

8 Dickson MD, Mazer RB: Pit and fissure sealant application with hydrophilic primer microleakage assessment (abstract). J Dent Res 2001;80:196.

9 Garcia-Godoy F, Carranza F: Clinical evaluation of flowrestore used as a fissure sealant (abstract). J Dent Res 2001;80:200.

10 Kwon HB, Park KT: SEM and microleakage evaluation of 3 flowable composites as sealant without using bonding agents. Pediatr Dent 2006;28:48-53.

11 Duangthip D, Lussi A: Variables contributing to the quality of fissure sealants used by general dental practitioners. Oper Dent 2003;28:756-764.

12 Corona SAM, Borsatto MC, Garcia L, Ramos RP, Palma-Dibb RG: Randomized controlled trial comparing the retention of a flowable restorative system with a conventional resin sealant: one-year follow-up. Int J Paediatr Dent 2005;15:44-50.

13 Dukić W, Dukić OL, Milardović S, Vindakijević Z: Clinical comparison of flowable composite to other fissure sealing materials - a 12 months study. Coll Antropol 2007; 31:1019-1024.
14 Dukić W, Glavina D: Clinical evaluation of three different materials for fissure sealing after 12 months. Acta Med Croat 2006;60: 209-214

15 Dukić W, Glavina D: Clinical evaluation of three fissure sealants: 24 month follow-up. Eur Arch Paediatr Dent 2007;8:163-166.

16 Beun S, Bailly C, Devaux J, Leloup G: Rheological properties of flowable resin composites and pit and fissure sealants. Dent Mater 2008;24:548-555.

17 Horowitz HS, Heifetz B, Poulsen S: Retention and effectiveness of a single application of an adhesive sealant in preventing occlusal caries: final report after five years of a study in Kalispel, Montana. J Am Dent Assoc 1977; 95:1133-1139.

18 Irinoda Y, Matsumura Y, Kito H, Nakano T, Toyama T, Nakagaki H, Tsuchiya T: Effect of sealant viscosity on the penetration of resin into etched human enamel. Oper Dent 2000; 25:274-282.

19 Love WC, Smith RS, Jackson E, Knuckles BN, Patton M: The efficacy of dental sealants for an adult population. Oper Dent 1993;18: 195-202.

20 Yildız E, Dörter C, Efes B, Koray F: A comparative study of two fissure sealants: a 2-year clinical follow-up. J Oral Rehabil 2004;31:979-984. 